\title{
Places where preschoolers are (in)active: an observational study on Latino preschoolers and their parents using objective measures
}

Ester Cerin ${ }^{1,2^{*}} \mathbb{D}$, Tom Baranowski ${ }^{3}$, Anthony Barnett ${ }^{1}$, Nancy Butte ${ }^{3}$, Sheryl Hughes ${ }^{3}$, Rebecca E. Lee ${ }^{4}$, Jason A. Mendoza ${ }^{5}$, Debbe Thompson ${ }^{3}$ and Teresia Margareta O'Connor ${ }^{3}$

\begin{abstract}
Background: To combat the disproportionately higher risk of childhood obesity in Latino preschool-aged children, multilevel interventions targeting physical (in) activity are needed. These require the identification of environmental and psychosocial determinants of physical (in) activity for this ethnic group. The objectives were to examine differences in objectively-measured physical activity and sedentary behavior across objectively-determined types of locations in Latino preschool-aged children; and determine whether the differences in physical activity by location were greater in children of parents with higher neighborhood-safety perceptions and physical activity-supportive parenting practices.

Methods: An observational field study was conducted in Houston (Texas, USA) from August 2011 to April 2012. A purposive sample of Latino children aged 3-5 years and one of their parents $(n=84)$ were recruited from Census block groups in Houston (Texas) stratified by objectively-assessed high vs. low traffic and crime safety. Seventy-three children provided valid data. Time spent outdoors/indoors tagged with geographic locations was coded into location types based on objective data collected using Global Positioning Systems units that children wore $>8 \mathrm{hr} /$ day for a week. Physical activity parenting practices, perceived neighborhood-safety, and demographics were reported by parents. Time spent in sedentary behavior and moderate-to-vigorous physical activity was measured based on objective data collected using accelerometers (motion sensors) that children wore $>8 \mathrm{hr} /$ day for a week.

Results: The odds of children engaging in moderate-to-vigorous physical activity were $43 \%$ higher when outdoors than indoors ( $95 \%$ confidence interval: 1.30, 1.58), and the odds of being sedentary were $14 \%$ lower when outdoors compared to indoors (95\% confidence intervals: $0.81,0.91$ ). This difference depended on parental neighborhood-safety perceptions and parenting practices. Children were most active in parks/playgrounds (30\% of the time spent in moderate-to-vigorous physical activity) and least active in childcare/school settings ( $8 \%$ of the time spent in moderate-to-vigorous physical activity).

Conclusions: Objectively-assessed time spent in specific locations is correlated with physical activity and sedentary behavior in Latino preschoolers. Interventions and policies should identify ways to engage Latino preschool-aged children in more physical activity and less sedentary behavior while in childcare, and encourage parents to spend more time with their young children in parks/playgrounds and other safe outdoor places.
\end{abstract}

Keywords: Physical activity locations, Global positioning system, Accelerometry, Preschool-aged children, Parenting practices, Neighborhood perceptions, Sedentary behavior

\footnotetext{
* Correspondence: ecerin@hku.hk

${ }^{1}$ Institute for Health and Ageing, Australian Catholic University, Melbourne,

VIC 3000, Australia

${ }^{2}$ School of Public Health, The University of Hong Kong, Hong Kong, Hong

Kong SAR, China

Full list of author information is available at the end of the article
} 


\section{Background}

Latinos are the fasted growing population in the United States (US) [1]. Compared to other ethnicities, Latino preschool-aged children have a disproportionately higher risk of childhood obesity [2] and show worse profiles of biomarkers related to cardiovascular disease risk in association with overweight/obesity [3]. Initiatives for increasing physical activity (PA) and reducing sedentary behavior (SB) have been acknowledged as key obesity prevention strategies in early childhood [4]. This also applies to Latino preschool children who were found to be more likely to have a healthy body mass index (BMI) if engaging in more moderate-to-vigorous physical activity (MVPA) [5]. Moreover, a recent integrative review on the determinants of obesity in this population concluded that decreased PA in Latino preschool-age children was a consistent contributor to obesity, while the evidence for nutrition-related factors (maternal feeding practices and beliefs, food choices) of obesity was inconsistent and inconclusive [6].

Both physical and social environmental factors influence young children's PA and SB [7-9]. Time spent outdoors, in parks or playgrounds was found to be one of the strongest predictors of children's PA [10-12]. Yet, with the exception of a small pilot study [12], this evidence pertained to non-Latino school-aged children, and was based on subjective proxy reports of child's location and/or activity, which are often inaccurate. Examining the locations where PA and SB occur specifically among Latinos is important because Latinos may relate to their neighborhood and surroundings differently compared to other ethnicities, emphasizing the need to understand the environmental context in which PA occurs among young Latino children. In fact, the current PA literature points to differences in exposure to environmental factors and associations of environment with PA between Latino and non-Latino children [13, 14]. For example, Latino preschool-aged children had less active-play equipment at home, spent less time outdoors, were exposed to more parental rules/restrictions for PA, and received less parental encouragement for PA than their Anglo-American counterparts [13]. Latino parents differed from the Anglo-American counterparts in the factors they used in selecting play spaces for their young children [15]. Ethnicity was also found to moderate the association between access to safe parks and engagement in regular PA [16].

The main aim of this study was therefore to estimate differences in accelerometry-assessed MVPA and SB between types of locations (e.g., home, childcare, park, outdoor, indoor) visited by a sample of Latino preschool-aged children residing in Harris County, Texas, a region with a large proportion of Hispanic or Latino population ( 42\% in 2013). In line with previous research, we hypothesized that children would be more active and less sedentary in places associated with fewer physical or social restrictions for PA, i.e., outdoors than indoors [13]; in parks/playgrounds than at home; and at home than at commercial establishments (e.g., businesses, shops and restaurants) [12].

Given that parental behavior and attitudes largely determine young children's opportunities for PA participation [17-20], a secondary aim of this study was to examine whether between-location differences in child's PA and SB depended on PA-related parenting practices and parental perceptions of neighborhood safety (moderators of location-PA and/or location-SB associations). We hypothesized that between-location differences in PA and SB would be greater in children of parents with more positive neighborhood-safety perceptions and parenting practices supportive of PA. This is because such parents might allow their children to be more active in appropriate places than parents who have safety concerns or do not encourage participation in PA. Additionally, we explored the moderating effects of child gender and weight status on the above between-location differences in children's PA and SB.

\section{Methods}

\section{Participants and recruitment}

Latino parents and their preschool-aged children (3-5 years old; one preschooler enrolled per family) were recruited from census block groups (Harris County, Texas) cross-stratified by objectively-assessed traffic and crime safety into four strata (low traffic/low crime; low traffic/ high crime; high traffic/low crime; high traffic/high crime). The number of participants per stratum (in the order presented above) was $25,16,13$, and 19 , and represented 56 different census block groups in Harris County. Details about the traffic and crime safety indices used to cross-stratify block groups were previously described [18]. This sampling strategy was adopted to maximize the variability of environmental exposures (neighborhood characteristics) and because neighborhood safety may impact children's PA and PA-related parental practices $[18,21]$. Parents or primary caregivers (here forth called parents) were recruited via various channels (e.g., community organizations). Eligibility criteria were being Latino and the parent of a Latino 3-5 year-old child living in the Houston area. Ethnicity was determined by self-identification as per US Census procedures [22] using the commonly-asked question "Are you Hispanic or Latino?". This question was asked twice: upon recruitment and during the study as part of a socio-demographic questionnaire. Exclusion criteria included: preschool children with a disease or disability preventing them from participating in PA, and parents who did not self-identify as Latino or were unable to 
read and write in English or Spanish. Eligible parents provided informed written consent (in Spanish or English) to participate in the study and allow their 3-5 year old child wear an accelerometer (PA monitor) and Global Positioning System (GPS) unit for a week. Data were collected from August 2011 to April 2012 (90\% during fall to spring; average high temperature range $62-95^{\circ} \mathrm{F}$; average low temperature range $41-74{ }^{\circ} \mathrm{F}$ ). Participants received $\$ 50$ in compensation for complying with the study protocol. The Baylor College of Medicine Institutional Review Board approved the study.

\section{Procedure}

Research staff met the participating parent and child in their home. After providing signed consent for themselves and permission for their child to participate, the parent completed a demographic questionnaire on a hard copy form and the rest of the questionnaires (see Survey Measures below) on a Personal Digital Assistant, after being assigned a participant code. The questionnaires were available in English and Spanish. Research staff were bilingual and gave participants the option of completing the questionnaires in English or Spanish. Only the preferred language version was provided to the participating parents.

Children's height (to the nearest $0.1 \mathrm{~cm}$; without shoes) and weight (to the nearest $0.1 \mathrm{~kg}$; without shoes and with light clothing) were measured twice by research staff. Children's BMI $\left(\mathrm{kg} / \mathrm{m}^{2}\right)$ was calculated and the US Centers for Disease Control and Prevention growth chart data were used to determine age- and gender-specific BMI z-scores [23].

Children simultaneously wore QStarz BT100X GPS units (QStarz International Co., Taiwan) and Actigraph GT3X accelerometers (Actigraph, Pensacola, USA) for a week. The clocks of the monitors were synchronized to the Universal Time Clock. PA data were collected at 15second epochs [24], while GPS data were collected at 30 -second epochs. The accelerometer was worn on the right hip, and the GPS unit on the left hip. Parents were instructed to remove the monitors before the child went to bed at night or engaged in water activities. They could remove the GPS unit whenever they did not want their child's location to be tracked. Parents documented in a standardized log when the child removed the monitors. Data documented as non-wear times and periods of $30+$ minutes of recorded zero accelerometer counts were removed from analysis. Accelerometer data were considered 'valid' if there were $\geq 480 \mathrm{~min}$ of activity data/day for $4+$ days, including one weekend day. Participants with invalid accelerometer data were asked to re-wear the monitors for additional days. Allowing for re-wears, 82 of the 84 children enrolled (96\%) had valid accelerometer data, and 73 of them also had valid (non- missing) GPS data on locations visited (geographical coordinates). Sixty-six of these 73 children also had valid GPS data on whether they were indoors, outdoors, or in vehicle (see below). The socio-demographic characteristics of these two groups (73 and 66 children) are reported in Table 1 . No substantial differences in sociodemographics (child's age and gender; parental age, gender, educational attainment, employment status, household income, and language spoken at home) were found between participants with valid vs. non-valid GPS data $(\mid$ Cohen's $\mathrm{d} \mid<0.20)$.

\section{Measures}

\section{Survey measures}

Parents completed a survey (in Spanish or English) validated in a large sample of Latino parents of preschoolaged children $(n=240)$ including the participants of this study [17]. The survey encompassed a sociodemographic questionnaire, PA parenting practices, and perceived aspects of neighborhood safety (signs of physical and social disorder; traffic safety and hazards; and stranger danger). PA parenting practices were assessed using the Preschooler's Physical Activity Parenting Practices instrument [17] with five subscales: one measuring parenting practices encouraging child PA (15 items), the others measuring parenting practices that discourage child PA [promote inactive transport (three items), promote screen time (three items), psychological control (manipulation of child's behavior to satisfy the parents' needs; four items), and restriction for safety concerns (four items)]. This instrument had good factorial validity and test-retest reliability (ICCs: 0.56-0.85) [17]. Perceived signs of physical and social disorder were assessed using a modified version of the 'Disorder' sub-scale from the Neighborhood Context scale [25] with 16 items rated on a 5-point scale [18]. Perceived traffic safety (3 items), traffic hazards (four items), and stranger danger (four items) were measured using an adaptation of the Neighborhood Environment Walkability Scale for Youth (NEWS-Y) with items rated on a 4-point Likert scale $[18,26]$. The scales had moderate-to-excellent test-retest reliability [18]. The mean ratings on the items of each scale were used for the analyses.

\section{Accelerometer and global positioning system data}

Accelerometer data were processed using Pate's cut points for preschool children [27] to determine sedentary time and MVPA, whereby $<76$ and $\geq 840$ accelerometer counts per 30 -second epochs were respectively classified as sedentary time and MVPA. Additionally, accelerometer counts collapsed to 30-second epochs provided a measure of "overall PA". Accelerometer data were merged to GPS data. 
Table 1 Parent and Child Socio-Demographics, Physical Activity (PA)-Related Parenting Practices, and Parental Perceived Neighborhood Safety

\begin{tabular}{|c|c|c|}
\hline Variables & Whole sample $(n=73)$ & $\begin{array}{l}\text { Sub-sample with GPS- estimated } \\
\text { outdoor/indoor time }(n=66)\end{array}$ \\
\hline Parent characteristics ears (mean, SD) & $32.3(6.1)$ & $31.5(5.6)$ \\
\hline Age, mean (SD) & $32.6(6.8)$ & $32.9(6.8)$ \\
\hline Born in the US, $n(\%)$ & $30(41 \%)$ & $27(41 \%)$ \\
\hline \multicolumn{3}{|l|}{ Country of origin, n (\%) } \\
\hline Mexico & $54(74 \%)$ & $49(74 \%)$ \\
\hline El Salvador & $9(12 \%)$ & $8(12 \%)$ \\
\hline Other Latin American countries & $10(14 \%)$ & $9(14 \%)$ \\
\hline \multicolumn{3}{|l|}{ Education, n (\%) } \\
\hline$<$ High School & $19(26 \%)$ & $17(26 \%)$ \\
\hline High School/GED & $28(39 \%)$ & $26(39 \%)$ \\
\hline > High School & $25(34 \%)$ & $23(35 \%)$ \\
\hline Not answered & $1(1 \%)$ & NA \\
\hline \multicolumn{3}{|l|}{ Current employment status, n (\%) } \\
\hline Not employed & $45(62 \%)$ & $42(64 \%)$ \\
\hline Employed & $27(37 \%)$ & $24(36 \%)$ \\
\hline Not answered & $1(1 \%)$ & $\mathrm{n} / \mathrm{a}$ \\
\hline \multicolumn{3}{|l|}{ Total household income, n (\%) } \\
\hline$\leq \$ 19 k$ & $25(34 \%)$ & $23(35 \%)$ \\
\hline$\$ 20 \mathrm{k}-\$ 49 \mathrm{~K}$ & $32(44 \%)$ & $29(44 \%)$ \\
\hline$\geq \$ 50 k$ & $12(16 \%)$ & $10(15 \%)$ \\
\hline Unknown/No answer & $4(6 \%)$ & $2(6 \%)$ \\
\hline \multicolumn{3}{|c|}{ Primary language spoken in household, n (\%) } \\
\hline English & $9(12 \%)$ & $8(12 \%)$ \\
\hline Spanish & $35(48 \%)$ & $32(48 \%)$ \\
\hline Both & $29(40 \%)$ & $26(40 \%)$ \\
\hline \multicolumn{3}{|l|}{ Child characteristics } \\
\hline Age in years, mean (SD) & $4.5(0.8)$ & $4.5(0.8)$ \\
\hline Gender, n (\%) Male & $42(58 \%)$ & $38(58 \%)$ \\
\hline \multicolumn{3}{|l|}{ Weight status, n (\%) } \\
\hline Normal weight & $35(48 \%)$ & $32(48 \%)$ \\
\hline Overweight & $15(21 \%)$ & $13(20 \%)$ \\
\hline Obese & $23(31 \%)$ & $21(32 \%)$ \\
\hline \multicolumn{3}{|c|}{ Hours/week spent in childcare center, n (\%) } \\
\hline None & $45(62 \%)$ & $40(60 \%)$ \\
\hline Up to 10 hours & $5(7 \%)$ & $4(6 \%)$ \\
\hline $11-20$ hours & $9(12 \%)$ & $9(14 \%)$ \\
\hline $21+$ hours & $14(19 \%)$ & $13(20 \%)$ \\
\hline \multicolumn{3}{|l|}{ PA parental practices ${ }^{\mathrm{a}}$, mean (SD) } \\
\hline Parental engagement and structure & $3.52(0.56)$ & $3.53(0.55)$ \\
\hline Promote screen time & $2.41(0.79)$ & $2.40(0.79)$ \\
\hline Promote inactivity & $1.71(0.56)$ & $1.69(0.56)$ \\
\hline Psychological control & $1.90(0.59)$ & $1.90(0.62)$ \\
\hline Restriction for safety concern & $2.74(1.01)$ & $2.77(1.01)$ \\
\hline
\end{tabular}


Table 1 Parent and Child Socio-Demographics, Physical Activity (PA)-Related Parenting Practices, and Parental Perceived Neighborhood Safety (Continued)

\begin{tabular}{lll}
\hline Perceived neighborhood safety, mean (SD) & & $2.94(0.71)$ \\
Traffic safety $^{\mathrm{b}}$ & $2.94(0.74)$ & $2.79(0.84)$ \\
Traffic hazards $^{\mathrm{b}}$ & $2.73(0.86)$ & $2.53(1.08)$ \\
Stranger danger $^{\mathrm{b}}$ & $2.51(1.10)$ & $2.22(0.87)$ \\
Signs of physical and social disorder $^{\mathrm{a}}$ & $2.17(0.86)$ & \\
\hline
\end{tabular}

Notes: All children were born in the US and participating parents were mothers; GED general educational development, SD standard deviation. ${ }^{\mathrm{a}}$ possible range: 1-5. ${ }^{\mathrm{b}}$ possible range: $1-4$

Although full-day PA guidelines for preschool aged children have not been published in the US, and other countries' PA recommendations vary as to their PA intensity recommendations for preschool-aged children [28], we used MVPA as an outcome because prior studies have associated MVPA rather than total lightmoderate-vigorous PA (LMVPA) with a lower likelihood of overweight/obesity in Latino preschool-aged children [5, 29], and Latino preschool-aged children have higher prevalence of overweight/obesity and worse CVD-risk biomarker profiles associated with overweight/obesity than other US ethnic groups [6]. Additionally, wear time-adjusted accelerometer-assessed sedentary time represents the other side of the coin of wear timeadjusted accelerometer-assessed LMVPA, as the accelerometer count cut-point for SB is also the cut-point for LMVPA. Thus, in this study, all the findings pertaining to SB apply to LMVPA but in the opposite direction (i.e., a negative association between time spent outdoors and SB indicates a positive association between time spent outdoors and LMVPA).

Data from both monitors were processed using the Personal Activity Location Measurement System, (PALMS) version 1.4.0 (https://ucsd-palms-project.wikispaces.com/) [30, 31]. PALMS is an encrypted web application that simultaneously processes time-stamped accelerometer and GPS data to clean, filter, and detect locations and trips based on study specified settings and established algorithms. Locations where participants spent 3+ minutes were identified in PALMS for GPS coordinates falling within a $30 \mathrm{~m}$ buffer [31]. The locations identified in PALMS were viewed using Google Earth and coded into the following eight categories of destinations: home, other locations in apartment complex, other residential home, childcare/school/daycare, park/ playground, any business/service without outdoor play area, any business/service with outdoor play area, and outside Houston. Multiple location points within a $50 \mathrm{~m}$ buffer from each participant's home, other residential homes, or business/services without outdoor play area, were coded as one location [32]. Multiple location points within a $100 \mathrm{~m}$ buffer from each childcare center, school or day-care center were also treated as a single location
[32]. Twenty percent of the participants' processed data were coded for location by two independent coders with a corresponding Kappa of 0.85 (95 \% CI: 0.81-0.89) indicating excellent agreement.

PALMS also identified participants' trips between locations. Mode of travel differentiated vehicular vs. nonvehicular trips, with motorized vehicle speed cut-off of $25 \mathrm{~km} / \mathrm{h}$ as per PALMS previously validated default settings [33]. Indoor, outdoor and in-vehicle location points were also identified using PALMS validated algorithms [34], which we found to have good sensitivity $(82 \%)$ and specificity (77 \%) in Houston.

\section{Data analyses}

Descriptive statistics were computed for socio-demographic characteristics, moderator variables (e.g., parental perceived neighborhood safety), participant-aggregated $\mathrm{PA}$ and $\mathrm{SB}$ variables, and participant-aggregated contextual (location) variables. Participant-aggregated variables were computed to provide an overview of children's daily average levels of $\mathrm{PA}$ and $\mathrm{SB}$ and time spent in various types of locations. Participant-aggregated PA and SB variables included: average min/day of SB and MVPA; average accelerometer counts per $30 \mathrm{~s}$; percentage of accelerometer wear time spent sedentary and in MVPA. Participant-aggregated contextual variables included the percentage of valid accelerometer/GPS time spent outdoors, indoors, in vehicle, in transit, and at eight types of locations. We computed percentage time spent in childcare/school/daycare for all participants as well as for only those whose parents reported they were enrolled in childcare/school/daycare. To examine whether time spent in different locations and average daily PA and SB differed by child's gender and weight status, generalized linear models with robust standard errors accounting for census block group clustering [35].

\section{Associations of contextual variables with physical activity and sedentary behavior}

Thirty-second epoch-level rather than participantaggregated data were used to examine associations of contextual variables with PA and SB. Epoch-level PA and $\mathrm{SB}$ variables included accelerometry counts per $30 \mathrm{~s}$, engaging in SB in a specific $30 \mathrm{~s}$ epoch (no $=0$; yes $=1$ ), 
and engaging in MVPA in a specific $30 \mathrm{~s}$ epoch (no = 0; yes $=1$ ). Epoch-level location (exposure) variables encompassed two categorical variables: indoor/outdoor/ in vehicle (indoor $=$ reference category), and location type (home $=$ reference category).

Given the large amount of data and the need to account for temporal and spatial autocorrelation [36], regression models of PA and SB could not be performed simultaneously on all participants, but were run for each participant separately. This yielded two regression models (one with outdoor/indoor/in vehicle as the predictor, the other with eight location types as the predictor) per participant per outcome (MVPA, SB and accelerometer counts per $30 \mathrm{~s}$ ), for a total of six regression models per child. Generalized additive mixed models (GAMMs) [37] were the type of regression models used for this purpose. GAMMs were used because they can model counts (accelerometer counts per $30 \mathrm{~s}$ epochs) as well as binary variables (engaging or not engaging in MVPA and SB) while accounting for spatial and temporal autocorrelation [37].

GAMMs of accelerometer counts per $30 \mathrm{~s}$ used a negative binomial distribution and a logarithmic link function (appropriate for positively skewed count variables). The other two PA outcomes were binary and were modelled using a binomial distribution and a logit link function. All GAMMs accounted for dependency at the day level (the fact that PA and SB may vary across different days). To account for correlated errors at successive within-day time points a correlation structure with a continuous autoregressive process of order 1 was used [37]. Residual spatial correlation was accounted for by including in the GAMMs a non-parametric smooth interaction term of the geographical coordinates (longitude and latitude) corresponding to participants' locations at specific 30-second epochs. GAMMs were conducted in $\mathrm{R}$ using the package 'mgcv' [37]. Adjustment for spatial and temporal residual correlation was necessary to obtain valid estimates of regression coefficients and standard errors [36-38].

After obtaining participant-specific estimates of associations of the two contextual variables with $\mathrm{PA}$ and $\mathrm{SB}$ using the GAMMs described above, it was necessary to synthesize the findings for the whole sample. To achieve this, the participant-specific regression coefficients and standard errors variance-covariance matrices obtained from the above GAMMs were entered in metaregression models (i.e., a meta-analysis with predictor variables). These meta-regression models treated the sample of participants as a random sample of 'studies' (each participant representing one study) with multiple correlated findings [39]. 'A finding' corresponded to the difference in a participant's mean outcome (e.g., accelerometer counts per $30 \mathrm{~s}$ ) between the reference category for a location (e.g., indoors) and another type of location (non-reference e.g., outdoors). Two sets of metaregression models were constructed, one for each of the two categorical contextual variables used in this study (indoor/outdoor/in vehicle; types of locations). These meta-regression models provided estimates of the average associations between contextual and $\mathrm{PA} / \mathrm{SB}$ variables for the whole sample. Meta-regression models of indoor vs. outdoor time also examined child gender, child weight status, PA-related parenting practices, and parental perceptions of neighborhood safety as potential moderators of the associations between being indoors/ outdoors and the PA/SB outcomes. This was done by entering the moderators as predictors in the metaregression models. The moderating effects of these variables on the associations between location types and PA/ SB outcomes were not examined because the number of children visiting location types other than home was small (7 to 71 children; Table 2). Statistically significant moderators were investigated by estimating the associations of contextual and PA/SB variables at three different values of the moderator (mean and \pm 1 standard deviation from the mean). Meta-regressions were conducted in $\mathrm{R}$ using the procedures outlined by Hox [39] and the package 'metafor' [40]. A probability level of 0.05 was adopted.

\section{Results}

Table 2 shows the descriptive statistics of all PA and contextual variables. Participating children spent, on average, $84(\mathrm{SD}=40)$ minutes per day in MVPA, corresponding to $12 \%$ of the time they wore the accelerometers $(>10 \mathrm{~h} /$ day $)$. They spent $53 \%$ of the remaining overall monitor-wear time in sedentary activities. Home was the location children spent, on average, most of their monitor-wear time (57 \%), followed by childcare/ school/daycare (30 \% for children enrolled in childcare; $22 \%$ for children visiting such a facility during the study; $14 \%$ for the whole sample, which includes those that never visited childcare setting), and other residential locations. Only $18 \%$ of the children spent time in a park during the study week, which represented $4 \%$ of their total monitor-wear time. No differences between weightstatus categories were observed in the examined variables. Only between-gender differences in time spent in locations in the apartment complex other than home and outside Houston were found (Additional file 1). In children who had valid outdoor/indoor GPS data, $59 \%$ of valid GPS/accelerometer wear time was spent indoors $(\sim 6.5$ out of $10.5 \mathrm{~h})$ and $35 \%$ outdoors $(\sim 3.5 \mathrm{~h})$. Locations that were associated with a larger proportion of outdoor time were parks/playgrounds ( $88 \%$ ) followed by being out of town (78\%), while childcare/school/daycare were the locations associated with the lowest percentage 
Table 2 Descriptive Statistics of Physical Activity, Sedentary Behavior and Contextual Variables

\begin{tabular}{|c|c|c|}
\hline Variables & Whole sample $(n=73)$ & $\begin{array}{l}\text { Sub-sample with GPS- estimated } \\
\text { outdoor/indoor time }(n=66)\end{array}$ \\
\hline \multicolumn{3}{|l|}{ Accelerometry/GPS data validity } \\
\hline Accelerometer wear time, min/day (SD) & $702(66)$ & $702(67)$ \\
\hline Valid days of accelerometer wear (SD) & $6.5(1.3)$ & $6.4(1.2)$ \\
\hline Accelerometer/GPS valid data, min/day (SD) & $644(85)$ & $647(86)$ \\
\hline Valid days of accelerometer/GPS data (SD) & $6.4(1.2)$ & $6.4(1.2)$ \\
\hline \multicolumn{3}{|l|}{ Physical activity variables } \\
\hline Sedentary, min/day (SD) & $371(70)$ & $371(69)$ \\
\hline MVPA, min/day (SD) & $84(40)$ & $86(41)$ \\
\hline Counts per 30 seconds (SD) & $313(119)$ & $320(123)$ \\
\hline$\%$ time sedentary $^{\mathrm{a}}$ & $53(8)$ & $53(8)$ \\
\hline$\%$ time in in MVPA ${ }^{a}$ & $12(5)$ & $12(5)$ \\
\hline \multicolumn{3}{|l|}{ Contextual variables } \\
\hline \multicolumn{3}{|l|}{$\%$ time spent outdoors/indoors/in vehicle $(S D)^{b}$} \\
\hline Outdoors & - & $35(20)$ \\
\hline Indoors & - & $59(22)$ \\
\hline \multirow[t]{2}{*}{ In vehicle } & - & $6(5)$ \\
\hline & Whole sample $(n=73)$ & In those visiting a location $[\mathrm{n}]^{\mathrm{c}}$ \\
\hline \multicolumn{3}{|l|}{$\%$ time at specific locations $(S D)^{b}$} \\
\hline No fixed location (in transit/trips) & $12(7)$ & $12(7)[73]$ \\
\hline Home & $57(22)$ & $57(22)[73]$ \\
\hline Other locations in apartment complex & $2(5)$ & $4(7)[29]$ \\
\hline Other residential home & $7(12)$ & $9(13)[58]$ \\
\hline \multirow[t]{2}{*}{ Child-care/school/daycare } & $14(14)$ & $22(15)[45]$ \\
\hline & & $30(10)[28]^{d}$ \\
\hline Park/playground & $1(2)$ & $4(5)[13]$ \\
\hline Other (any business/service) without outdoor play area & $5(5)$ & $5(5)[71]$ \\
\hline Other (any business/service) with outdoor play area & $1(5)$ & $3(7)[39]$ \\
\hline Outside Houston & $1(3)$ & $8(9)[7]$ \\
\hline
\end{tabular}

Notes: ${ }^{a} \%$ time refers to $\%$ of valid accelerometry time. ${ }^{b} \%$ time refers to $\%$ of valid accelerometry/GPS unit time. ${ }^{c}$ Number of children who visited specific locations within the study period varied and is reported in square brackets [n]; ${ }^{d}$ In children whose parents reported they were enrolled in child-care/school/ daycare. GPS global positioning system, MVPA moderate-to-vigorous physical activity, SD standard deviation

of outdoor time in children enrolled (13\%) and not enrolled (14\%) in childcare/school/daycare (Table 3) [Note:, a few children whose parents had reported on the demographic survey they did not attend childcare/ school/daycare, were found to spend time in these types of locations during the study period according to GPS data].

\section{Associations of contextual variables with physical activity and sedentary behavior}

Children were most active outdoors and least active when in a vehicle. The latter findings serves as a validation for the PALMS web application which used GPS data to identify time spent walking, being stationary in a specific location, and in motorized trips (in a moving vehicle). The odds of children engaging in MVPA were $43 \%$ higher when outdoors than indoors, and the odds of being sedentary were $14 \%$ lower when outdoors, compared to indoors (Table 4). When compared to home, where children spent most of their time, being in other locations in the apartment complex and at a park/ playground was associated with higher levels of PA and less sedentary time (Table 5). Being at a park/playground predicted $84 \%$ higher average accelerometer counts than being at home, and the odds of engaging in MVPA were $341 \%$ higher than when at home. Time spent at other residential homes were associated with lower odds of being sedentary but not with higher odds of MVPA. Being in any business or service was associated with lower levels of activity but not with lower odds of being 
Table 3 Percentage of Time Spent at Specific Locations by Time Spent Outdoors/Indoors/In Vehicle $(n=66)$

\begin{tabular}{|c|c|c|c|c|}
\hline \multirow[t]{2}{*}{ Location } & \multirow[b]{2}{*}{$\mathrm{n}$} & \multirow{2}{*}{$\begin{array}{l}\text { Outdoors } \\
\text { Mean (SD) }\end{array}$} & \multirow{2}{*}{$\begin{array}{l}\text { Indoors } \\
\text { Mean (SD) }\end{array}$} & \multirow{2}{*}{$\begin{array}{l}\text { In vehicle } \\
\text { Mean (SD) }\end{array}$} \\
\hline & & & & \\
\hline No fixed location (in transit/trips) & 66 & $12(14)$ & $4(5)$ & $84(15)$ \\
\hline Home & 66 & $36(18)$ & $64(24)$ & $0(0)$ \\
\hline Other locations in apartment complex & 23 & $39(20)$ & $58(22)$ & $3(3)$ \\
\hline Other residential home & 52 & $36(20)$ & $63(21)$ & $1(1)$ \\
\hline \multirow[t]{2}{*}{ Child-care/school/daycare } & 41 & $14(13)$ & $85(12)$ & $1(1)$ \\
\hline & $26^{\mathrm{a}}$ & $13(14)$ & $86(17)$ & $1(1)$ \\
\hline Park/playground & 13 & $88(10)$ & $10(9)$ & $2(2)$ \\
\hline Other (any business/service) without outdoor play area & 64 & $40(20)$ & $56(25)$ & $4(3)$ \\
\hline Other (any business/service) with outdoor play area & 34 & $28(21)$ & $70(21)$ & $2(1)$ \\
\hline Outside Houston & 5 & $78(10)$ & $19(11)$ & $3(3)$ \\
\hline
\end{tabular}

Notes. SD standard deviation. $n$ number of participants (children) that visited specific locations within the study period. ${ }^{\mathrm{a}}$ In children whose parents reported they were enrolled in child-care/school/daycare

sedentary. Being in a childcare center or school was associated with the lowest level of activity and the highest odds of being sedentary of all other locations (Table 5).

\section{Moderators of associations}

Two PA-related parenting practices and two aspects of perceived neighborhood safety moderated the associations of PA outcomes with being outdoors vs. indoors (Fig. 1). Significant differences in accelerometry counts and odds of engaging in MVPA between indoor and outdoor locations were found only in children of parents who infrequently used psychological control as a practice to discourage child's PA (Fig. 1, panels a and b). Significant indoor vs. outdoor differences in odds of being sedentary were found only in children of parents with average or lower scores on the parenting PAdiscouraging practices of psychological control and restrictions for safety concerns, and on perceived signs of physical and social disorder, and above average scores on perceived traffic safety (Fig. 1, panel c).

\section{Discussion}

In line with previous research in other populations $[10,11,41-43]$, being in outdoor locations predicted children being more active than being in indoor locations. This was particularly the case for parks, playgrounds, and out-of-home locations within a residential complex. Yet, only one in five children visited a park or playground during the 7-day study period, and $40 \%$ of children spent time in locations surrounding a residential complex for fewer than 30 min per day. Low proportions of daily PA located in parks and playgrounds have been previously reported in older children [44, 45], and have been attributed to poor park/playground accessibility and quality. As a recent study on preschoolers' PA in childcare centers noted [43], PA interventions aiming to increase young children's outdoor time at suitable and safe locations hold promise. These interventions may need to focus on enhancing the accessibility of safe outdoor places for play as well as increasing parents' and preschool teachers' awareness of the importance of spending more time with children outdoors $[44,45]$.

As previously observed, business/service locations were associated with lower levels of PA likely due to parents controlling their child's behavior to a greater extent, or fewer opportunities for active play in such settings [17]. Yet, children were even less active in school and childcare settings, where enrolled children, on average, spent $\sim 21 \mathrm{~h} /$ week, and

Table 4 Physical Activity and Sedentary Behavior Outcomes by Indoor, Outdoor and 'In Vehicle' Locations $(n=66)$

\begin{tabular}{|c|c|c|c|c|c|c|c|}
\hline \multirow[t]{2}{*}{ Physical activity outcomes } & \multicolumn{3}{|c|}{ Descriptive statistics - mean (SD) } & \multicolumn{4}{|c|}{$\begin{array}{l}\text { Meta-regression analyses - average regression coefficient } \\
\text { ( } 95 \% \text { confidence intervals) }^{a}\end{array}$} \\
\hline & Indoors & Outdoors & In vehicle & Indoors vs Outdoors & $p$ & Indoors vs In vehicle & $p$ \\
\hline Accelerometer counts per 30 seconds & $313(525)$ & $361(594)$ & $121(239)$ & $1.13(1.09,1.16)$ & $<.001$ & $0.56(0.51,0.62)$ & $<.001$ \\
\hline Engaging in sedentary behavior (\% time) & $46(50)$ & $43(50)$ & $64(48)$ & $0.86(0.81,0.91)$ & $<.001$ & $1.59(1.38,1.82)$ & $<.001$ \\
\hline Engaging in MVPA (\% time) & $11(35)$ & $14(35)$ & $2(15)$ & $1.43(1.30,1.58)$ & $<.001$ & $0.39(0.34,0.45)$ & $<.001$ \\
\hline
\end{tabular}

Note: MVPA moderate-to-vigorous physical activity. \% time refers to \% of valid accelerometry/GPS time. SD standard deviation represents the total within- and

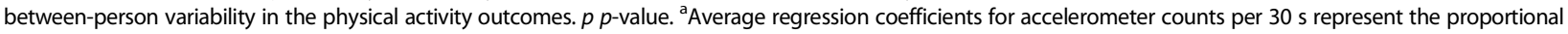
difference between average accelerometer counts when indoors vs. outdoors, and when indoors vs. in vehicle. Average regression coefficients for sedentary behavior and MVPA represent the odds ratios of engaging in such activities when indoors vs outdoors and when indoors vs in vehicle. Individual regression models (that were included in the meta-regression) were adjusted for temporal and spatial autocorrelation 
Table 5 Physical Activity and Sedentary Behavior Outcomes by Location Types $(n=73)$

\begin{tabular}{|c|c|c|c|c|c|c|c|}
\hline \multirow{3}{*}{$\begin{array}{l}\text { Location type } \\
\text { Descriptive statistics }\end{array}$} & \multirow{3}{*}{$\mathrm{n}$} & \multicolumn{6}{|c|}{ Physical activity outcome } \\
\hline & & \multicolumn{2}{|l|}{$\begin{array}{l}\text { Accelerometer counts } \\
\text { per } 30 \text { seconds }\end{array}$} & \multicolumn{2}{|l|}{$\begin{array}{l}\text { Engaging in sedentary } \\
\text { behavior (\% time) }\end{array}$} & \multicolumn{2}{|l|}{$\begin{array}{l}\text { Engaging in MVPA } \\
\text { (\% time) }\end{array}$} \\
\hline & & \multicolumn{2}{|l|}{ Mean (SD) } & \multicolumn{2}{|l|}{ Mean (SD) } & \multicolumn{2}{|l|}{ Mean (SD) } \\
\hline Home & 73 & $337(560)$ & & $45(50)$ & & $12(33)$ & \\
\hline Other locations in apartment complex & 29 & $386(472)$ & & $32(47)$ & & $15(35)$ & \\
\hline Other residential home & 58 & $361(556)$ & & $41(49)$ & & $13(34)$ & \\
\hline Child-care/school/daycare & 45 & $247(418)$ & & $51(50)$ & & $8(27)$ & \\
\hline $\begin{array}{l}\text { Child-care/school/daycare - in enrolled children } \\
\text { only }\end{array}$ & 28 & $227(386)$ & & $51(50)$ & & $7(26)$ & \\
\hline Park/playground & 13 & $645(716)$ & & $24(43)$ & & $30(46)$ & \\
\hline $\begin{array}{l}\text { Other (any business/service) without outdoor play } \\
\text { area }\end{array}$ & 71 & $276(448)$ & & $47(50)$ & & $9(29)$ & \\
\hline Other (any business/service) with outdoor play area & 39 & $262(441)$ & & $49(50)$ & & $9(29)$ & \\
\hline Meta-regression analyses ${ }^{a}$ & & $e^{b}(95 \% \mathrm{Cl})$ & $p$ & OR $(95 \% \mathrm{Cl})$ & $p$ & OR $(95 \% \mathrm{Cl})$ & $p$ \\
\hline \multicolumn{8}{|l|}{ Home (reference category) vs ... } \\
\hline Other locations in apartment complex & & $1.25(1.08,1.45)$ & .003 & $0.67(0.56,0.80)$ & $<.001$ & $1.31(1.08,1.59)$ & .006 \\
\hline Other residential home & & $1.01(0.88,1.17)$ & .887 & $0.81(0.69,0.96)$ & .011 & $1.12(0.95,1.32)$ & \\
\hline Child-care/school/daycare & & $0.64(0.56,0.74)$ & $<.001$ & $1.26(1.07,1.49)$ & .006 & $0.67(0.57,0.78)$ & $<.001$ \\
\hline $\begin{array}{l}\text { Child-care/school/daycare - in enrolled children } \\
\text { only }\end{array}$ & & $0.78(0.70,0.87)$ & $<.001$ & $1.23(1.03,1.54)$ & .022 & $0.66(0.53,0.83)$ & $<.001$ \\
\hline Park/playground & & $1.84(1.48,2.28)$ & $<.001$ & $0.37(0.30,0.47)$ & $<.001$ & $4.41(3.28,5.85)$ & $<.001$ \\
\hline $\begin{array}{l}\text { Other (any business/service) without outdoor play } \\
\text { area }\end{array}$ & & $0.83(0.72,0.97)$ & .010 & $1.02(0.82,1.14)$ & .859 & $0.83(0.71,0.99)$ & .019 \\
\hline Other (any business/service) with outdoor play area & & $0.78(0.67,0.91)$ & .001 & $1.04(0.87,1.25)$ & .746 & $1.00(0.82,1.22)$ & .999 \\
\hline
\end{tabular}

Notes: Locations outside Houston and no fixed locations/trips excluded from the analyses; \% time refers to \% of valid accelerometry/GPS time; $n$ number of participants (children) that visited specific locations during the monitoring period, MVPA moderate-to-vigorous physical activity, GPS global positioning system, SD standard deviation representing the total within- and between-person variability in the physical activity outcomes, OR odds ratio, $95 \% \mathrm{Cl} 95 \%$ confidence intervals, $e^{b}$ anti-logarithm of regression coefficient, $p p$-value. ${ }^{a}$ Antilogarithms of average regression coefficients $\left(e^{b}\right)$ for accelerometer counts per 30 seconds represent the proportional difference between average accelerometer counts when home vs at other locations. Average regression coefficients for sedentary behavior and MVPA represent the odds ratios of engaging in such activities when home vs at other locations. Individual regression models (that were included in the meta-regression) were adjusted for temporal and spatial autocorrelation

more than half of that time was devoted to sedentary activities. In fact, schools and childcare centers were the places with the lowest level of PA, the highest level of SB, and the lowest percentage of outdoor time. While low levels of PA in preschool settings have been previously reported [42, 46-48], only one other recent study conducted in the United Kingdom (UK) has compared preschoolaged children's PA and SB levels in school/childcare settings with other locations, albeit using parental reports to determine time spent in and out of childcare [49]. In the UK study, higher levels of activity were observed in childcare as compared to home. These have been attributed to the introduction of 'free-flow' policies allowing children in childcare to freely move indoors and outdoors for most of the day irrespective of weather conditions [49]. The low levels of PA in childcare observed in the present study are sobering given the increasing proportion of Latino preschoolers in childcare in the US (from $12 \%$ in 2006 to $21 \%$ in 2011) [50, 51], coupled with the number of hours many children spend in this environment ( $29 \mathrm{~h} /$ week) [50]. Interventions and policies should identify ways to engage preschool children in more MVPA and less SB while in childcare [43].

As postulated by socio-ecological models [52], this study suggests that built and social environmental factors interact to shape Latino preschool-aged children's PA and SB. Differences in PA and SB between outdoor and indoor locations depended on parental attitudes and practices related to neighborhood safety. These findings suggest that parents may restrict children's spontaneous tendency to be more active outdoors if they perceive their neighborhood to be unsafe. It is thus important to provide access to objectively safe outdoor environments where parents can take their children to play and, at the same time, help parents with overprotective tendencies build more realistic and positive perceptions about the safety of these environments for their child to play. In a previous study on the same sample, we found that parental psychological control (i.e., manipulation of child's behavior to satisfy the parents' needs) was positively 


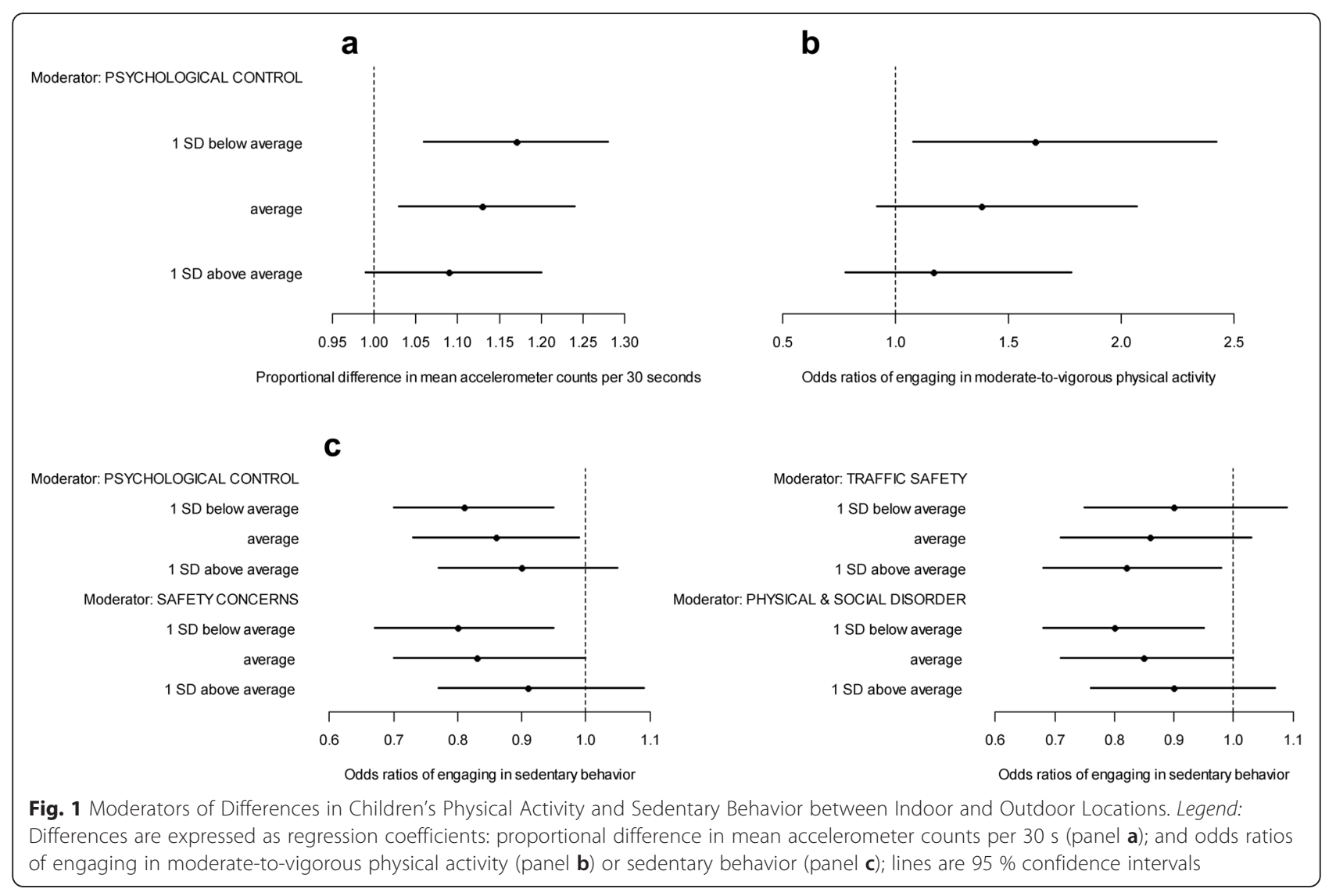

related to children's PA [18]. In this study, high levels of psychological control were associated with smaller differences in PA and SB between outdoor and indoor locations. Parents of children who are spontaneously more active may tend to use psychological control to restrict their level of activity in general, which would explain why their children had similar levels of PA and SB in different contexts.

According to recent Australian, Canadian, and UK PA guidelines for preschool-age children [53], our sample exceeded the daily recommendation of $180 \mathrm{~min}$ of PA (usually operationalized as LMVPA). Similar levels of PA have been reported in other recent investigations on Latino [54] and other young children [55]. It remains to be seen whether the associations observed in this study hold in less active subgroups of children. Given that leading an active lifestyle can only be beneficial to health and that PA levels decline as children approach adolescence [56], investigating environmental factors that promote PA in this population remains an important public health issue.

This is the first study to use accelerometer and GPS monitors to capture objective data on locations, PA, and SB over a 1-week period in Latino preschool-aged children's habitual environment. It is the first study to adjust for both spatial and temporal autocorrelation in determining the potential effect of different contexts on children's PA and SB, thus, providing very robust estimates of associations. Limitations are the use of a nonprobability sampling; a relatively small sample size; the correlational nature of the study not allowing establishment of causality; the lack of information on the social context in the various types of locations visited by the child (i.e., the person(s) a child was with); and the potential misclassification of outdoor vs. indoor time. This study estimated that children spent on average $\sim 3.7 \mathrm{~h}$ per day outdoors, which seems high. Yet, using the same method, Tandon and colleagues [34] found that preschoolers spent outdoors $\sim 1 \mathrm{~h}$ of their childcare time. A diary-based study conducted in Baltimore indicated an average of $\sim 3.1 \mathrm{~h}$ of outdoor time in inner city preschool-aged children [57], while in Canada only $\sim 2 \mathrm{~h}$ were reported [58]. A better climate in this study site (Houston; fall to spring) than in the other studies may account for more time spent outdoors. With regards to the lack of information on the social context associated with various types of locations, it is important to note that the presence of specific people (e.g., siblings, friends, parents, teachers, etc.) may affect a child's activity level and, thus, the associations of specific types of location with children's MVPA and SB [59,60]. Future studies will need to establish the extent to which the 
social context confounds or moderates the differences in MVPA and SB across different types of locations.

\section{Conclusions}

Latino preschool-aged children, irrespective of gender and weight status, were most active outdoors, and while in parks or playgrounds; and least active in school/childcare settings Differences in levels of children's activity between outdoor and indoor settings were smaller if parents had less favorable perceptions regarding the safety of their neighborhood environment, and used parenting practices discouraging children's PA. Interventions and policies should identify ways to engage Latino preschool-aged children in more physical activity and less sedentary behavior while in childcare, and encourage parents to spend more time with their young children in parks/playgrounds and other safe outdoor places.

\section{Additional file}

Additional file 1: Table S1. Descriptive Statistics of Physical Activity and Contextual Variables by Child's Gender. (DOCX $21 \mathrm{~kb}$ )

\begin{abstract}
Abbreviations
BMI: body mass index; CVD: cardiovascular disease; GAMMs: generalized additive mixed models; GPS: global positioning system; ICC: intraclass correlation; LMVPA: light, moderate and vigorous physical activity; MVPA: moderate-to-vigorous physical activity; NEWS-Y: neighborhood environment walkability scale for youth; PA: physical activity; PALMS: personal activity location measurement system; SB: sedentary behavior; SD: standard deviation; UK: United Kingdom; US: United States.
\end{abstract}

\section{Competing interests}

TMO serves as a consultant for the National Institutes of Health and has received payment for the development of educational presentations by PriMed CME. NB declares UpToDate royalties. The remaining authors declare that they have no potential conflicts of interest to disclose.

\section{Authors' contributions}

EC conceived the study, wrote the grant application, participated in meetings of co-investigators, conceptualized and performed the data analyses, and wrote the initial draft. TB, participated in the conceptualization of the study, and meetings of co-investigators. $A B$ participated in the conceptualization of the data analyses and processed the data for the meta-regression. NB and SH participated in the conceptualization of the study and in meetings of the co-investigators, and made valuable contributions. REL coordinated the work related to the objective measurement of neighborhood environmental attributes used for the stratification of participants, and participated in the conceptualization of the study and in meetings of the co-investigators. JAM and DT participated in the meetings of co-investigators, and made many valuable contributions. TMO was the principal investigator of the project, participated in the conceptualization of the study, chaired the meetings of co-investigators, and coordinated the study. All the co-authors critically reviewed early drafts of the manuscript and provided final review of the manuscript to be published. EC and TMO had full access of the data in the study and take responsibility for the integrity of the data and the accuracy of the analysis. All authors read and approved the final manuscript.

\section{Acknowledgments}

EC is supported by an Australian Research Council Future Fellowship (\# 140100085). This study was funded by NIH-Eunice Kennedy Shriver National Institute of Child Health \& Human Development (R21HD060925).
This work is a publication of the US Department of Agriculture (USDA/ARS) Children's Nutrition Research Center, Department of Pediatrics, BCM through a cooperative agreement (USDA/ARS 6250-51000-053-20S). The contents of this publication do not necessarily reflect the views or policies of the USDA or $\mathrm{NIH}$, nor does mention of organizations imply endorsement from the US government. The study sponsors had no role in study design and conduct of the study; collection, management, analysis, and interpretation of data; and preparation, review or approval of the manuscript.

\section{Author details}

${ }^{1}$ Institute for Health and Ageing, Australian Catholic University, Melbourne, VIC 3000, Australia. '2 School of Public Health, The University of Hong Kong, Hong Kong, Hong Kong SAR, China. ${ }^{3}$ USDA/ARS Children's Nutrition Research Center, Department of Pediatrics, Baylor College of Medicine, Houston, TX, USA. ${ }^{4}$ Center for Health Promotion and Disease Prevention, College of Nursing and Health Innovation, Arizona State University, Phoenix, Arizona, USA. ${ }^{5}$ Department of Pediatrics, University of Washington and the Seattle Children's Research Institute, Seattle, WA, USA.

Received: 29 September 2015 Accepted: 25 February 2016

Published online: 29 February 2016

\section{References}

1. Ennis S, Rios-Vargas M, Albert N. The Hispanic population: 2010. Suitland: U. S. Department of Commerce, Economics and Statistics Administration, US Census Bureau; 2011.

2. Ogden $\mathrm{CL}$, Carroll MD, Kit BK, Flegal KM. Prevalence of obesity and trends in body mass index among US children and adolescents, 1999-2010. JAMA. 2012;307:483-90.

3. Messiah SE, Arheart KL, Natale RA, Hlaing WM, Lipshultz SE, Miller TL. BMI, waist circumference, and selected cardiovascular disease risk factors among preschool-age children. Obesity. 2012;20:1942-9.

4. Lambourne K, Donnelly JE. The role of physical activity in pediatric obesity. Pediatr Clin North Am. 2011;58:1481-91.

5. Schaefer SE, Camacho-Gomez R, Sadeghi B, Kaiser L, German JB, de la Torre A. Assessing child obesity and physical activity in hard-to-reach population in California's Central Valley, 2012-2013. Prev Chronic Dis. 2015;12:E117.

6. Innella N, Breitenstein S, Hamilton R, Reed M, McNaughton DB. Determinants of obesity in the Hispanic preschool population: An integrative review. Public Health Nurs. 2015; doi:10.1111/phn.12215.

7. Dolinsky DH, Brouwer RJ, Evenson KR, Siega-Riz AM, Østbye T. Correlates of sedentary time and physical activity among preschool-aged children. Prev Chronic Dis. 2011;8:A131.

8. Dowda M, Pfeiffer KA, Brown WH, Mitchell JA, Byun W, Pate RR. Parental and environmental correlates of physical activity of children attending preschool. Arch Pediat Adol Med. 2011;165:939-44.

9. Lovasi GS, Jacobson JS, Quinn JW, Neckerman KM, Ashby-Thompson MN, Rundle A. Is the environment near home and school associated with physical activity and adiposity of urban preschool children? J Urban Health. 2011;88:1143-57.

10. Ferreira I, van der Horst K, Wendel-Vos W, Kremers S, van Lenthe FJ, Brug J. Environmental correlates of physical activity in youth - a review and update. Obes Rev. 2007:8:129-54.

11. Klinker CD, Schipperijn J, Kerr J, Ersbø\|l AK, Troelsen J. Context-specific outdoor time and physical activity among school-children across gender and age: using accelerometers and GPS to advance methods. Front Public Health. 2014;2:20.

12. O'Connor TM, Cerin E, Robles J, Lee RE, Kerr J, Butte N, et al. Feasibility study to objectively assess activity and location of Hispanic preschoolers: a short communication. Geospat Health. 2013;7:375-80.

13. Sallis JF, Nader PR, Broyles SL, Berry CC, Elder JP, McKenzie TL, et al. Correlates of physical activity at home in Mexican-American and AngloAmerican preschool children. Health Psychol. 1993;12:390-8.

14. Drukker M, Buka SL, Kaplan C, McKenzie K, Van Os J. Social capital and young adolescents' perceived health in different sociocultural settings. Soc Sci Med. 2005;61:185-98.

15. Sallis JF, McKenzie TL, Elder JP, Broyles SL, Nader PR. Factors parents use in selecting play spaces for young children. Arch Pediatr Adolesc Med. 1997;151:414-7.

16. Babey SH, Hastert TA, Yu H, Brown R. Physical activity among adolescents: when do parks matter? Am J Prev Med. 2008;34:345-8. 
17. O'Connor TM, Cerin E, Hughes SO, Robles J, Thompson DI, Mendoza JA, et al. Psychometrics of the preschooler physical activity parenting practices instrument among a Latino sample. Inter J Behav Nutr Phys Act. 2014;11:3.

18. O'Connor TM, Cerin E, Lee RE, Parker N, Chen TA, Hughes SO, et al. Environmental and cultural correlates of physical activity parenting practices among Latino parents with preschool-aged children: Niños Activos. BMC Public Health. 2014;14:707.

19. Pocock M, Trivedi D, Wills W, Bunn F, Magnusson J. Parental perceptions regarding healthy behaviours for preventing overweight and obesity in young children: a systematic review of qualitative studies. Obes Rev. 2010;11:338-53.

20. Ruiz R, Gesell SB, Buchowski MS, Lambert W, Barkin SL. The relationship between Hispanic parents and their preschool-aged children's physical activity. Pediatrics. 2011;127:888-95.

21. Davison KK, Lawson CT. Do attributes of the physical environment influence children's physical activity? Inter J Behav Nutr Phys Act. 2006:3:19.

22. Humes KR, Jones NA, Ramirez RR. Overview of race and Hispanic origin: 2010. 2010 Census Briefs. Suitland: U.S. Department of Commerce, Economics and Statistics Administration, US Census Bureau; 2011.

23. Kuczmarski RJ, Ogden CL, Guo SS, Grummer-Strawn LM, Flegal KM, Mei Z, et al. 2000 CDC Growth Charts for the United States: methods and development. Vital Health Stat. 2002;11:1-190.

24. Cliff DP, Reilly JJ, Okely AD. Methodological considerations in using acceleromters to assess habitual physical activity in children aged $0-5$ years. J Sci Med Sports. 2009;12:557-67.

25. Coulton CJ, Korbin JE, Su M. Measuring neighborhood context for young children in an urban area. Am J Community Psychol. 1996;24:5-32.

26. Rosenberg D, Ding D, Sallis JF, Kerr J, Norman GJ, Durant N, et al. Neighborhood Environment Walkability Scale for Youth (NEWS-Y): reliability and relationship with physical activity. Prev Med. 2009;49:213-8.

27. Pate RR, Almeida MJ, Mclver KL, Pfeiffer KA, Dowda M. Validation and calibration of an accelerometer in preschool children. Obesity. 2006;14:2000-6.

28. Institute of Medicine. Early childhood obesity prevention policies. Washington: The National Academies Press; 2011.

29. Mendoza JA, McLeod J, Chen TA, Nicklas TA, Baranowski T. Correlates of adiposity in Latino preschool children. J Phys Act Health. 2014;11:195-8.

30. Patrick K, Kerr J, Norman G, Ryan S, Sallis J, Krueger, et al. Geospatial measurement \& analysis of physical activity: Physical Activity Location Measurement System (PALMS). Epidemiology. 2008;19:S63. ISEE 2008 Conference Abstracts Supplement.

31. Kerr J, Duncan S, Schipperjin J. Using global positioning systems in health research: a practical approach to data collection and processing. Am J Prev Med. 2011;41:532-40.

32. Oreskovic NM, Blossom J, Field AE, Chiang SR, Winickoff JP, Kleinman RE. Combining global positioning system and accelerometer data to determine the locations of physical activity in children. Geospatial Health. 2012;6:263-72.

33. Kerr J, Norman G, Godbole S, Raab F, Kerr J, Demchak B, et al. Validating GPS data with the PALMS system to detect different active transportation modes. Med Sci Sport Exer. 2012;44:S647.

34. Tandon PS, Saelens BE, Zhou C, Kerr J, Christakis DA. Indoor versus outdoor time in preschoolers at child care. Am J Prev Med. 2013;44:85-8.

35. Cerin E. Statistical approaches to testing the relationships of the built environment with resident-level physical activity behaviour and health outcomes in cross-sectional studies with cluster sampling. J Plan Lit. 2011;26:151-67.

36. Cressie NAC, Wikle C. Statistics for spatio-temporal data. Hoboken: Wiley; 2011.

37. Wood SN. Generalized additive models: An Introduction with R. Boca Raton: Chapman \& Hall; 2006

38. Dubin RA. Spatial autocorrelation: a primer. J Housing Econ. 1998;7:304-27.

39. Hox JJ. Multilevel analysis: techniques and applications. New York: Routledge; 2010.

40. Viechtbauer W. Conducting meta-analyses in $\mathrm{R}$ with the metaphor package. J Stat Software. 2010;36(3):1-48

41. Oreskovic NM, Perrin JM, Robinson Al, Locascio JJ, Blossom J, Chen ML, et al. Adolescents' use of the built environment for physical activity. BMC Public Health. 2015;15:251.

42. Raustorp A, Pagels P, Boldemann C, Cosco N, Söderström F, Måtensson F. Accelerometer measured level of physical activity indoors and outdoors during preschool time in Sweden and the United States. J Phys Act Health. 2012;9:801-8.

43. Tandon PS, Saelens BE, Christakis DA. Active play opportunities at child care. Pediatrics. 2015;135:e1425-31.

44. Quigg R, Gray A, Reeder Al, Holt A, Walters DL. Using accelerometers and GPS units to identify the proportion of daily physical activity located in parks with playgrounds in New Zealand children. Prev Med. 2010;50:235-40.

45. Dunton GF, Almanza E, Jerrett M, Wolch J, Pentz MA. Neighborhood park use by children: use of accelerometry and global positioning systems. Am J Prev Med. 2014;46:136-42

46. Pate RR, O'Neill JR, Byun W, Mclver KL, Dowda M, Brown WH. Physical activity in preschool children: comparison between Montessori and traditional preschools. J Sch Health. 2014;84:716-21.

47. Pate RR, Pfeiffer KA, Trost SG, Ziegler P, Dowda M. Physical activity among children attending preschools. Pediatrics. 2004;114:1258-63.

48. Vanderloo LM. Screen-viewing among preschoolers in childcare: a systematic review. BMC Pediatr. 2014;14:205.

49. Hesketh KR, Griffin SJ, van Sluijs EMF. UK preschool-aged children's physical activity levels in childcare and at home: a cross-sectional exploration. Int J Behav Nutr Phys Act. 2015;12:33.

50. National Association of Child Care Resources and Referral Agencies. Latino Parents' Perceptions of Child Care in the United States. Arlington: NACCRRA; 2008

51. U.S. Census Bureau. Who is minding the kids? child care arrangements 2011 detailed tables. Washington: US Census Bureau; 2013. http://www.census. gov/programs-surveys/sipp/data/tables/2008-panel/2011-tables.htm Accessed 20 April, 2015.

52. Sallis JF, Owen N, Fisher EB. Ecological models of health behavior. In: Glanz K, Rimer BK, Viswanath K, editors. Health behavior and health education: theory, research, and practice. 3rd ed. San Francisco: Jossey-Bass; 2008. p. 465-86

53. Tremblay MS, LeBlanc AG, Carson V, Choquette L, Gorber SC, et al. Canadian physical activity guidelines for the early years (aged $0-4$ years). Appl Physiol Nutr Metab. 2012;37:345-56.

54. Dawson-Hahn EE, Fesinmeyer MD, Mendoza JA. Correlates of physical activity in Latino preschool children attending Head Start. Pediatr Exerc Sci. 2015:27:372-9

55. Konstabel K, Veidebaum T, Verbestel V, Moreno LA, Bammann K, et al. Objectively measured physical activity in European children: the IDEFICS study. Int J Obes. 2014;38:S135-43.

56. Dumith SC, Gigante DP, Dominigues MR, Kohl HW. Physical activity change during adolescents: a systematic review and a pooled analysis. Int J Epidemiol. 2011:40:685-98.

57. Bose S, Breysse PN, McCormack MC, Hansel NN, Rusher RR, Matsui E. Outdoor exposure and vitamin D levels in urban children with asthma. Nutr J. 2013;12:81.

58. Matz CJ, Stieb DM, Davis K, Egyed M, Rose A, Chou B, et al. Effects of age, season, gender and urban-rural status on time-activity: Canadian Human Activity Pattern Survey 2 (CHAPS 2). Int J Environ Res Public Health. 2014;11:2108-24.

59. Bagley S, Salmon J, Crawford D. Family structure and children's television viewing and physical activity. Med Sci Sports Exerc. 2006;38:910-8.

60. Ziviani J, Macdonald D, Jenkins D, Rodger S, Batch J, Cerin E. Physical activity of young children. OTJR: Occupat Participation Health. 2006;26:4-14

\section{Submit your next manuscript to BioMed Central and we will help you at every step:}

- We accept pre-submission inquiries

- Our selector tool helps you to find the most relevant journal

- We provide round the clock customer support

- Convenient online submission

- Thorough peer review

- Inclusion in PubMed and all major indexing services

- Maximum visibility for your research

Submit your manuscript at www.biomedcentral.com/submit 